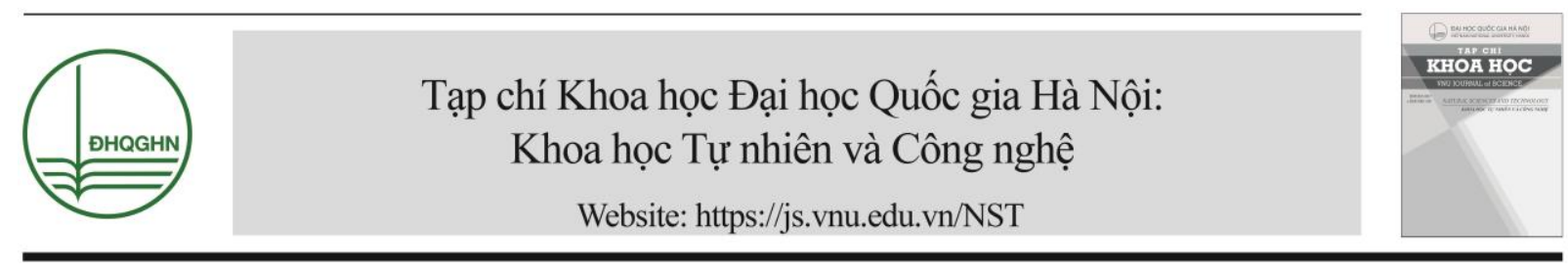

\title{
Nghiên cứu phân lập nấm rễ nội cộng sinh Arbuscular Mycorrhiza trong đất trồng ngô và sản xuất chế phẩm phân bón vi sinh
}

\author{
Lê Thị Hoàng Yến ${ }^{1, *}$, Lê Hồng Anh ${ }^{1}$, \\ Mai Thị Đàm Linh ${ }^{2}$, Dương Văn Hợp ${ }^{1}$ \\ ${ }^{1}$ Viện Vi sinh vật và Công nghệ Sinh học, ĐHQGHN,144 Xuân Thủy, Hà Nội, Việt Nam \\ ${ }^{2}$ Truò̀ng Đại học Khoa học Tự nhiên, ĐHQGHN, 334 Nguyễn Trãi, Thanh Xuân, Hà Nội, Việt Nam \\ Nhận ngày 08 tháng 5 năm 2018 \\ Chỉnh sửa ngày 15 tháng 6 năm 2018; Chấp nhận đăng ngày 09 tháng 8 năm 2018
}

\begin{abstract}
Tóm tắt: Từ 30 mẫu đất trồng ngô ( 15 mẫu đất trồng ngô ở Hà Nội và 15 mẫu đất trồng ngô ở Hà $\mathrm{Nam}$ ), chúng tôi đã phân lập được 3179 bào tử $\mathrm{AMF}$. Bằng phương pháp phân loại dựa vào hình thái, chúng tôi đã xếp chúng vào 8 chi và 27 loài: Acaulospora gerdemanii, A. mellea, A. morrowiae, A. rehmii, Acaulospora longula, Acaulospora sp.1, Acaulospora sp.2, Acaulospora sp.3, Cetraspora pellucida, Dentiscutata sp., Dentiscutata reticulata, Gigaspora albida, G. decipiens, G. gigantea, G. margarita, Glomus ambisporum, G. multicaule, G. luteum, G.intraradices, Glomus sp., Rhizophagus gregaria, R. clarus, Rhizophagus sp., S. constrictum, New AMF 1, New AMF 2, New AMF 3; trong đó có 03 chi 9 loài được nghi là mới, Dentiscutata, Racocetra, Rhizophagus và Septoglomus là những chi lần đầu tiên được công bố ở Việt Nam. Chi Acaulospora, Gigaspora và Glomus là các chi có tần suất xuất hiện cao nhất ở mẫu đất cát ở Hà Nội và Hà Nam từ 13,4 - 40,2\%. Bốn loài A. longula, G. decipiens, G. Gingatea và Glomus multicaule được tiến hành lựa chọn để nghiên cứu khả năng cộng sinh của chúng lên cây chủ trên các môi trường gồm cát, xơ dừa và đất dinh dưỡng được được trộn với tỉ lệ khác nhau. Kết quả cho thấy môi trường có tỉ lệ cát/ xơ dừa/ đất dinh dưỡng với tỉ lệ 1:1:1 là môi trường thích hợp nhất cho sự cộng sinh của $\mathrm{AMF}$ vào cây chủ. Kiểm tra số lượng bào tử sau 5 tuần nuôi cấy cho thấy: Acaulospora là loài có khả năng xâm nhiễm cao nhất, tiếp đó là Gingaspora và Glomus số lượng bào tử của Gingaspora và Acaulospora đạt từ $330-652$ bào tử/ $100 \mathrm{~g}$ cơ chất môi trường MT5. Sử dụng chế phẩm $\mathrm{AMF}$ để bổ sung vào ngô ngoài đồng ruộng cho thấy chế phẩm có khả năng xâm nhiê̂m vào cây chủ với chỉ số IP là 1217,8 , tăng $40 \%$ trọng lượng, $58,9 \%$ chiều cao thân ngô và 24,9\% trọng lượng bắp.
\end{abstract}

Tù khóa: Nấm rễ nội cộng sinh, nghiên cứu đa dạng, phân bón vi sinh, phân tích hình thái, rễ cây ngô.

\section{Mở đầu}

Nấm rễ nội cộng sinh (AMF-Arbuscular Mycorrhizal Fungi) là nhóm nấm có lợi trong

*Tác giả liên hệ. ĐT.: 84-388563454. đất và sống cộng sinh trong rễ của thực vật bậc cao, chúng đóng vai trò quan trọng trong quá trình phát triển của thực vật cũng như hệ sinh

Email: yenlth@vnu.edu.vn

https://doi.org/10.25073/2588-1140/vnunst.4743 
thái. AMF được phát hiện từ ít nhất 400 triệu năm trước, chúng có vai trò rất quan trọng đối với sự phát triển và sinh sản của cả thực vật và nấm. $\mathrm{AMF}$ được xem là nhóm vi sinh vật chủ yếu tồn tại ở rễ và đất của cây trồng, chúng được tìm thấy trong hầu hết các sinh cảnh trên toàn thế giới và trong khoảng $90 \%$ các loài thực vật [1]. Mặc dù là nội cộng sinh bắt buộc nhưng giữa nấm và thực vật được được coi là mối quan hệ "Hội sinh", do chúngmang lại lợi ích cho cả vật chủ và nấm. Trước hết, nấm nhận được các sản phẩm quang hợp từ thực vật bằng cách sống cố định trong rễ của chúng và sau đó phát triển mạng lưới hệ sợi nấm trong vùng bầu rễ để tạo thuận lợi cho việc hấp thụ các chất dinh dưỡng và cung cấp các chất có lợi khác cho vật chủ, cạnh tranh với các vi khuẩn trong đất khác, đồng thời giúp thực vật tăng khả năng lấy nước và chất dinh dưỡng như phốt pho, lưu huỳnh, nitơ và các vi chất dinh dưỡng từ các sợi nấm tạo ra ngoài vùng rễ. Ngoài ra sự cộng sinh của nấm còn giúp cây trồng có khả năng chống chịu được sự khô hạn,đề kháng với một số tác nhân gây bệnh [2].

Cây ngô là nhóm cây chủ lực của Việt Nam sau lúa, tuy nhiên không có nhiều nghiên cứu về đa dạng $\mathrm{AMF}$ trong đất trồng ngô ở Việt Nam cũng như mối tương quan giữa điều kiện môi trường sống tới sự đa dạng thành phần loài củaAMF. Do vậy, việc nghiên cứu đa dạng sinh học $\mathrm{AMF}$ trong đất trồng ngô ở những vùng khí hậu, đất đai thổ nhưỡng khác nhau, tìm được những loài ưu thế, loài đặc hữu, tìm hiểu sự liên quan giữa đa dạng $\mathrm{AMF}$ với các loại đất trồng khác nhau. Liệu có sự liên quan giữa đa dạng AMF và năng suất cây trồng khác nhau ở mô̂i vùng miền? Để trả lời cho câu hỏi đó, chúng tôi đã tiến hành thực hiện "Nghiên cúu phân lập nấm rễ nọi cộng sinh Arbuscular Mycorrhiza trong đất trồng ngồ và sản xuất chế phẩm phân bón vi sinh" với các mục tiêu: nghiên cứu đa dạng thành phần loài nấm Mycorrhiza tồn tại trong đất trồng ngô ở Thường Tín- Hà Nội và Duy Tiên- Hà Nam, đưa ra những đơn vị phân loại mới của nấm rễ nội cộng sinh có ở Việt Nam. Bước đầu nghiên cứu sản xuất và sử dụng, đánh giá hiệu quả phân bón vi sinh từ 03 chi nấm chiếm ưu thếđã phân lập được: Acaulospora, Gigaspora và Glomus.

\section{Nguyên vật liệu và phương pháp}

- Mẫu phân lập: 30 mẫu đất xung quanh rễ cây ngô, 15 mẫu được lấy ở Thường Tín-Hà Nội và 15 mẫu được lấy ở Duy Tiên- Hà Nam.

- Môi trường phân lập: Nước máy, nước cất khử trùng, môi trường MSR [3].

- Môi trường nhân nuôi AMF: Xơ dừa, Đất cát: Đất giàu dinh dưỡng: xơ dừa với các tî lệ khác nhau: 1:1:0,5 (MT1); 2:1:1 (MT2), 0:1:0 (MT3); 1:2:1 (MT4) và 1:1:1 (MT5).

- Phuoong pháp lấy mẫu đất: loại bỏ $3 \mathrm{~cm}$ lớp đất bề mặt xung quanh gốc cây ngô, sau đó lấy khoảng $500 \mathrm{~g}$ đất xung quanh mẫu tới độ sâu khoảng $20 \mathrm{~cm}$.

- Phưong pháp phân lập nấm AMF bằng kỹ thuật sàng ướt qua màng lọc có các kích thước khác nhau: $500,350,150$ và $50 \mu \mathrm{m}$ cùng với các thang nồng độ đường 30-50\% [4], kết hợp với phương pháp tách bào tử đơn độc[5].

- Phuoong pháp phân loại AMF dụa vào hình thái:

Bào tử sau khi phân lập được chia thành các nhóm tương đối đồng đều nhau dựa vào hình thái bề mặt. Sau đó chọn những bào tử đại diện, nhuộm bằng thuốc thử của Melzer [6, 7]; quan sát dưới kính hiển vi, mô tả màu sắc, kích thước, bề mặt và cấu trúc vách của bào tử, đối chiếu với các mô tả và hình ảnh của INVAM để xác định tên loài [8].

- Phân loại AMF dựa vào phân tích trình tự SSU ARNr đoạn AML1/AML2 [2].

-Phuoong pháp tính hiệu quả lây nhiếm của $A M F$ vào vật chủ [9].

Công thức được tính như sau:

$\mathrm{IP}=(\mathrm{N} \times \mathrm{W} \times \mathrm{K})+\mathrm{S}$

Trong đó, nhiễm

IP (infection potential) $=$ Khả năng lây

$\mathrm{N}=$ số lượng túi hoặc bào tử trong rễ/ 
hoặc điểm vào của sợi nấm .

$\mathrm{W}=$ trọng lượng gốc của rễ

$\mathrm{K}=$ chiều dài gốc trên đơn vị trọng lượng

$\mathrm{S}=$ số lượng bào tử xuất hiện trong gốc [6].

- Phương pháp nhân nuôi AMF trên quy mô phòng thí nghiệm và ngoài đồng ruộng [10].

\section{Kết quả và thảo luận}

\section{1. Đa dạng số loài nấm rễ nọi cộng sinh AMF} trên đất trồng ngô Hà Nội

Từ 30 mẫu đấ trồng ngô (15 mẫu đất lấy từ rễ và gốc cây ngô thu thập ở đất Thường TínHà Nội, 15 mẫu lấy ở đất xung quanh rễ cây ngô ở Duy Tiên- Hà Nam) bằng phương pháp sàng ướt kết hợp với phân lập bào tử đơn độc, chúng tôi đã phân lập được 3179 bào tử $\mathrm{AMF}$ (693 bào tử AMF từ đất trồng ngô Hà Nội, 2486 bào tử từ đất trồng ngô Hà Nam). Dựa trên kết quả phân tích hình thái bào tử, chúng được xếp vào 8 chi, 27 loài (Hà Nội có 8 chi, 15 loài, Hà Nam có 8 chi, 18 loài): Acaulospora gerdemanii, A. mellea, A. morrowiae, A. rehmii, A. longula, Acaulospora sp.1, Acaulospora sp.2, Acaulospora sp.3, Cetraspora pellucida, Dentiscutata sp., D. reticulata, Gigaspora albida, G. decipiens, G. gigantea, G. margarita, Glomus ambisporum, G. multicaule, G. luteum, G. intraradices, Glomus sp., Rhizophagus gregaria, $R$. clarus, Rhizophagus sp., $S$. constrictum, New AMF 1, New AMF 2, New $\mathrm{AMF} 3$; trong đó có 03 chi 9 loài được nghi là mới. Dentiscutata, Racocetra, Rhizophagus và Septoglomus là những chi lần đầu tiên được công bố ở Việt Nam.

Acaulospora; Dentiscutata; Gigaspora; Glomus là những chi chiếm ưu thế ở Hà Nội, tần suất xuất hiện lần lượt là $13,40 \% ; 15,46 \%$; 40,42\%; 13,40\%. Gigaspora decipiens, Gigasporagigantean, Glomus macrocarpum và Acaulospora longula là những loài chiếm ưu thế, tần suất xuất hiện lần lượt là: $20,62 \%$; 13,6 $\% ; 11,34 \%$ và $11,34 \%$. Acaulospora,
Gigaspora là những chi chiếm ưu thế, tần suất xuất hiện của chúng theo thứ tự lần lượt là: 37 $\%$; 29,1 \%. Gigaspora decipiens và $G$. gigantean là những loài chiếm ưu thế, tần suất xuất hiện lần lượt là: $11,8 \%$ và $12,6 \%$. Kết quả này khá tương đồng so với các nghiên cứu trước đó [11-13]. Nghiên cứu này cũng chỉ ra rằng đa dạng nấm rễ nội cộng sinh trên rễ cây ngô cao hơn so với một số loại cây lương thực khác (lúa, cà chua, cam...) ở Việt Nam. Chẳng hạn, năm 2012 Trần Thị Như Hằng [14] và cộng sự đã nghiên cứu đa dạng AMF trên rễ cây lúa và cây cà chua, các tác giả đã phát hiện được 5 chi: Scutellospora, Glomus, Acaulospora, Gigaspora và Entrophospora. Hay trong một nghiên cứu về đa dạng AMF trên rễ cây cam ở Quỳ Hợp, Nghệ An, từ 60 mẫu đất, các tác giả cũng chỉ phát hiện được 6 chi: Acaulospora, Entrophospora, Glomus, Sclerocystis, Glomites và Gigaspora), 16 loài. Tuy nhiên so với các nghiên cứu khác trên thế giới thì sự đa dạng $\mathrm{AMF}$ trong nghiên cứu của chúng tôi còn khá khiêm tốn: Zhang và cs 2003 đã tìm được 47 loài $\mathrm{AMF}$ từ đất khô hạn hay Wang và cộng sự (2008) đã tìm được 33 loài AMF từ đất ngập mặn [15].

3.2. Đa dạng AMF trong đất trồng ngô Hà Nội và Hà Nam dựa vào mật độ loài

Sự phân bố về mật độ loài-Species richness (SR) của 15 loài $\mathrm{AMF}$ trong 15 mẫu đất trồng ngô Hà Nội thể hiện trong Hình 3.1 cho thấy mật độ loài thay đổi từ 1-7 loài/mẫu (trung bình là 3,6 loài), trên các mẫu đất cát Hà Nội $6 ; 8 ; 9$ SR là từ $5-7$. Sự phân bố về mật độ loài của 15 loài AMF trong 15 mẫu đất trồng ngô Hà Nam là từ 6-15 loài/mẫu (trung bình là 8,73 loài), trong khi đó trên mẫu đất cát khô Hà Nam $1 ; 3$; 4; 6; 7 SR là từ 10-15.

Từ các kết quả của nghiên cứu này có thể nhận định rằng đặc điểm điều kiện tự nhiên ảnh hưởng đến tính đa dạng thành phần loài của $\mathrm{AMF}$ trong vùng sinh khái nghiên cứu giữa Hà Nội và Hà Nam khác nhau dẫn đến thành phần loài ở Hà Nam cao hơn hẳn so với Hà Nội. 


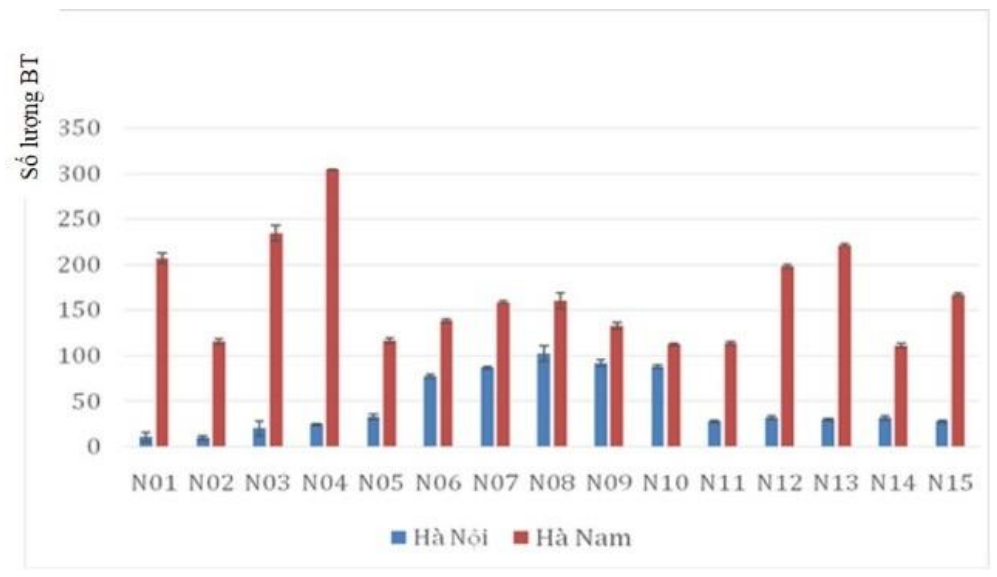

Hình 3.1. Mật độ loài AMF ở đất trồng ngô Hà Nội và Hà Nam.

Các nghiên cứu trước đây đã chỉ ra rằng có rất nhiều yếu tố có thể ảnh hưởng đến mật độ bào tử và sự phong phú của loài trong một khu hệ nấm rễ, chẳng hạn như tính thời vụ, các yếu tố hình thái, sự phụ thuộc vào cây chủ, tuổi cây chủ, khả năng hình thành bào tử của $\mathrm{AMF}$, và sự phân bố bào tử nấm $\mathrm{AMF}$ trong đất, mật độ bào tử nấm $\mathrm{AMF}$ liên kết với các cây khác nhau ở các địa điểm khác nhau $[2,6,7,10,16]$.

\subsection{Lựa chọn môi truờng thích hợp để sản xuất} in vitro nấm rễ nọi cộng sinh
Xơ dừa ngâm nước, khử trùng, để nguội, bổ sung hạt ngô đã làm sạch và ngâm qua đêm, sau đó tiêm 05 bào tử $A M F$ vào mỗi hạt ngô. Quan sát sự nảy mầm, phát triển của hạt trong vòng 01 tuần. Kết quả cho thấy, trong số 4 loại $\mathrm{AMF}$ bổ sung vào quá trình nuôi ngô trên xơ dừa cho thấy cả 4 loại AMF đều kích thích cây chủ sinh trưởng, phát triển, tuy nhiên Acaulospora longula là loài có khả năng xâm nhiễm vật chủ tốt nhất, có thể tăng kích thước chiều cao cây chủ nhiều nhất, gấp 4,5 lần so với đối chứng (Hình 3.2).

\subsubsection{Nhân nuôi AMF trong xơ dì̀a}

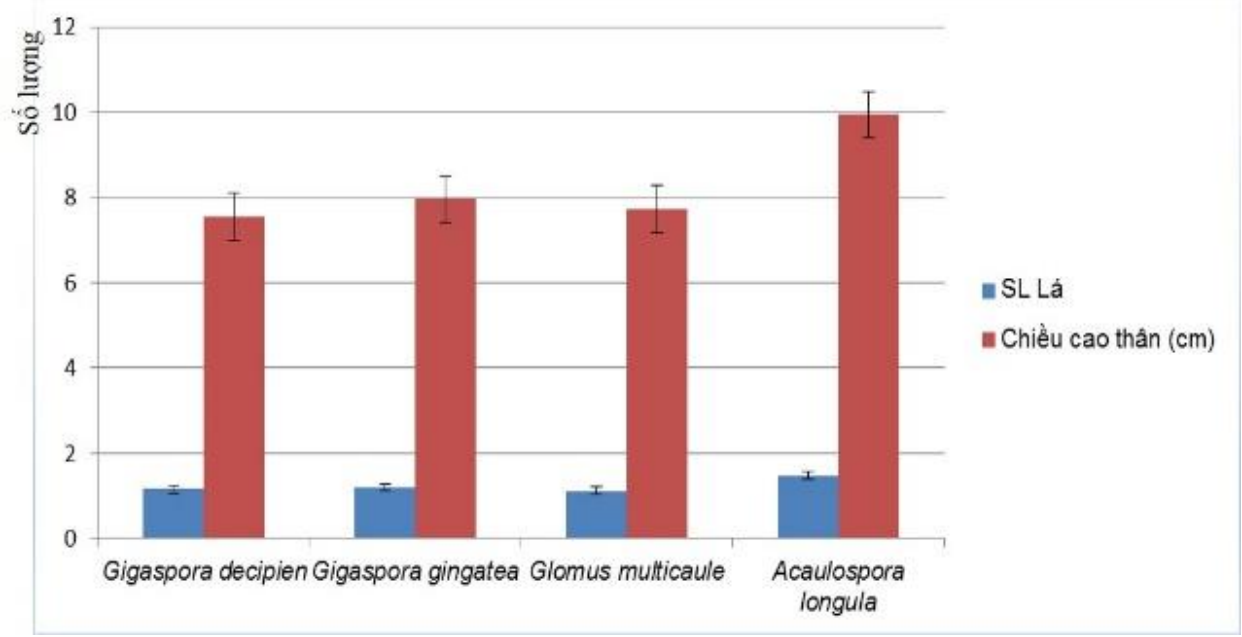

Hình 3.2. Ảnh hưởng của AMF lên sự phát triển của ngô khi nuôi trên xơ dừa. 
3.3.2. Nhân nuôi AMF vào cây ngô đã trồng trực tiếp trong cốc nhựa $100 \mathrm{~g}$ co chất

Chuẩn bị $100 \mathrm{~g}$ cơ chất môi trường nuôi cấy nấm rễ nội cộng sinh trong phòng thí nghiệm (MT1, MT2, MT3, MT4, MT5), khử trùng $121^{\circ} \mathrm{C}, 15$ phút, để nguội, cho vào cốc nhựa. Sau đó bổ sung mỗi cốc 02 hạt ngô đã khử trùng bề mặt, bổ sung lượng nước đủ ẩm mỗi ngày. Sau 5 ngày tiêm 05 bào tử $A M F$ Acaulospora longuta vào mỗi gốc cây. Tiếp tục chăm sóc và quan sát sinh trưởng, phát triển của cây, thu cây, kiểm tra trọng lượng cây, rễ và đếm số lượng bào tử. Kết quả cho thấy sự tăng trưởng của ngô có bổ sung AMF đã cao hơn ngô đối chứng: trọng lượng trung bình của thân ngô trong thí nghiệm gần gấp 2 lần thân ngô đối chứng, trọng lượng trung bình của rễ cũng tăng $50,04 \%$. (so với đối chứng). Môi trường MT5 gồm đất cát: đất dinh dưỡng: xơ dừa tỉ lệ 2:1:1 là môi trường thích hợp nhất cho sự phát triển của cây cũng như sự hình thành AMF (Bảng 3.1). Kết quả này tương tự báo cáo trước đó cho thấy khi bổ sung thêm AMF đã làm tăng số lượng lá, tổng trọng lượng tươi và trọng lượng khô của cây ngô con [17] Tuy nhiên phương pháp này chưa thu được số lượng bào tử $\mathrm{AMF}$ như mong muốn.

\subsubsection{Nghiên cứu phương pháp nuôi AMF trong bình chưa $350 \mathrm{~g}$ co chất}

Chuẩn bị các môi trường nuôi cấy nấm rễ nội cộng sinh trong phòng thí nghiệm (MT1, MT2, MT3, MT4, MT5), khử trùng $121^{\circ} \mathrm{C}, 15$ phút, để nguội, cho vào chậu đã chuẩn bị ở phần trên $350 \mathrm{~g}$ cơ chất. Chuyển bầu ngô xơ dừa đã bổ sung $\mathrm{AMF}$ được 01 tuần sang bình nhựa chứa $350 \mathrm{~g}$ cơ chất. Quan sát sự phát triển của cây ngô sau 5 tuần nuôi cấy, thu hoạch cây và AMF trong chậu nuôi cấy. Nghiên cứu ảnh hưởng của $\mathrm{AMF}$ lên sự phát triển của cây về chiều cao và trọng lượng thân ngô. Kết quả cho thấy A. longula, Glomus macrocarpum khi được nuôi trên môi trường MT5 là môi trường có thành phần dinh dưỡng gồm đất cát: đất giàu dinh dưỡng: xơ dừavới tỉ lệ 1 : 1 : 1 là môi trường thích hợp nhất cho sự sinh trưởng và phát triển của cây (Bảng 3.2a). Chiều cao cây $55-57 \mathrm{~cm}$ (tăng $57,14-62,86 \%$ so với đối chứng), trọng lượng cây 5,9-6,9 g (tăng 78,79$109,1 \%$ so với đối chứng). Trên môi trường MT2 (đất cát: đất giàu dinh dưỡng: xơ dừa với tỉ lệ 2: 1: 1), khi đó chiều cao thân của cả 2 loại ngô là $53 \mathrm{~cm}$, trọng lượng khô đạt $3,7-4,7 \mathrm{~g} /$ cây (Bảng 3.2b).

Bảng 3.1. Nhân nuôi AMF trên cốc nhựa trong phòng thí nghiệm

\begin{tabular}{lllll}
\hline & No. & Trọng lượng cây $(\mathbf{g})$ & Khối lượng rễ $(\mathbf{g})$ & Số bào tử AMF/ gốc \\
\hline \multicolumn{6}{c}{ MT1 } & $4.5742 \pm 2,2$ & $1.82 \pm 3,4$ & $120 \pm 1,5$ \\
Lô TN & MT2 & $2.4742 \pm 3,4$ & $0.83 \pm 1.6$ & $124 \pm 2,6$ \\
& MT3 & $3.87 \pm 0,7$ & $1.50 \pm 0.2$ & $132 \pm 3,5$ \\
& MT4 & $3.53 \pm 2,7$ & $1.43 \pm 2,2$ & $122 \pm 1,8$ \\
\multicolumn{6}{l}{ Trung bình } & MT5 & $\mathbf{5 . 4 7} \pm 1,1$ & $\mathbf{2 . 5 8} \pm 2,5$ & $\mathbf{1 2 5} \pm 2,1$ \\
Lô ĐC & 3,982 & 1,632 & 124,6 \\
\hline
\end{tabular}

Bảng 3.2a. Ảnh hưởng của AMH lên chiều cao của cây $(\mathrm{cm})$

\begin{tabular}{llllll}
\hline Chủng AMF & MT1 & MT2 & MT3 & MT4 & MT5 \\
\hline G.decipien & $43 \pm 2,2$ & $45 \pm 2,2$ & $42 \pm 2,2$ & $43,5 \pm 1,4$ & $45 \pm 1,2$ \\
G.gingatea & $47 \pm 1.1$ & $53 \pm 1,2$ & $43 \pm 1,5$ & $44 \pm 1,3$ & $50 \pm 0,8$ \\
A. longula & $44 \pm 1,2$ & $48 \pm 1,0$ & $43 \pm 2,2$ & $48 \pm 1,4$ & $57 \pm 2,2$ \\
Glomusmacro & $44 \pm 0,2$ & $53 \pm 3,2$ & $45 \pm 2,1$ & $43,5 \pm 2,1$ & $55 \pm 0,6$ \\
carpum & $39 \pm 1,3$ & $41 \pm 1,3$ & $32 \pm 2,2$ & $40 \pm 2,3$ & $35 \pm 0,9$ \\
ĐC & & & & & \\
\hline
\end{tabular}


Bảng 3.2b Ảnh hưởng của AMF lên trọng lượng khô của cây $(\mathrm{g})$

\begin{tabular}{llllll}
\hline Chủng AMF & MT1 & MT2 & MT3 & MT4 & MT5 \\
\hline G.decipien & $3,0 \pm 0,2$ & $3,3 \pm 1,2$ & $4,5 \pm 3,2$ & $3,3 \pm 2,3$ & $3,5 \pm 1,2$ \\
G.gingatea & $3,6 \pm 0,8$ & $3,7 \pm 0,5$ & $2,2 \pm 1,2$ & $3,0 \pm 1,5$ & $4,1 \pm 2,4$ \\
A. longula & $3,3 \pm 0,8$ & $3,6 \pm 0,6$ & $2,1 \pm 1,8$ & $3,6 \pm 0,9$ & $6,9 \pm 0,1$ \\
Glomusmacro & $3,2 \pm 2,2$ & $4,7 \pm 0,9$ & $3,2 \pm 2,7$ & $3,2 \pm 0,4$ & $5,9 \pm 2,2$ \\
carpum & $2,4 \pm 2,2$ & $3,2 \pm 2,2$ & $0,92 \pm 1,6$ & $1,8 \pm 0,2$ & $3,3 \pm 0,9$ \\
ĐC & & & & & \\
\hline
\end{tabular}

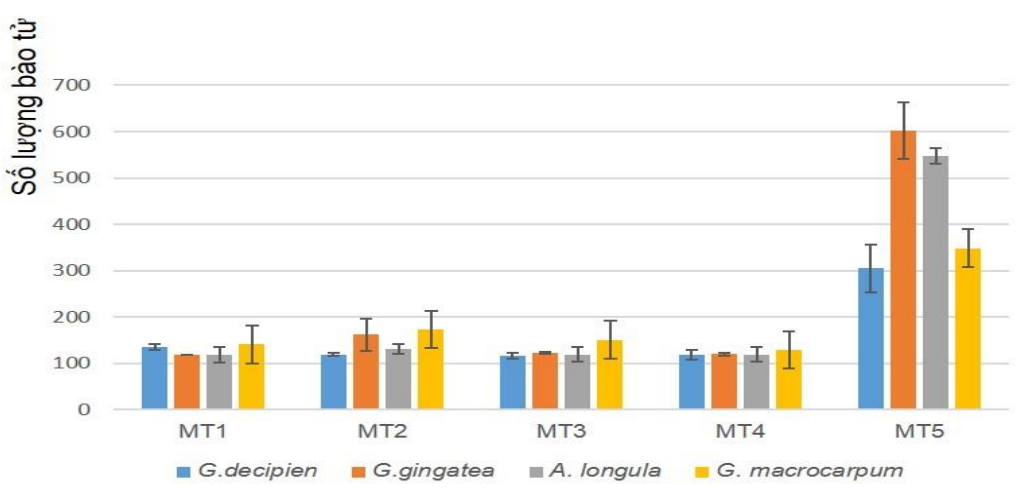

Hình 3.3. Số lượng bào tử AMF hình thành sau 5 tuần nuôi cấy.

Sau 5 tuần nuôi cấy $\mathrm{AMF}$ trên các môi trường nuôi cấy khác nhau, chúng tôi tiến hành thu và đếm số lượng bào tử. Nhận thấy: trên môi trường MT1-MT4 số lượng bào tử /bình là thấp, từ 114-173 bào tử, trung bình là 129,8 bào tử/gốc. Tuy nhiên khi nuôi trên môi trường MT5, số lượng bào tử tăng vọt đáng kinh ngạc, 330-652 bào tử/gốc, trung bình là 471,5 bào tử/gốc (gấp 3,6 lần) so với các môi trường còn lại (hình 3.3).

So sánh kết quả đạt được giữa việc nuôi $\mathrm{AMF}$ ở thể tích $100 \mathrm{~g}$ cơ chất và $350 \mathrm{~g}$ cơ chất cho thấy:khi nuôi trong cốc thể tích $100 \mathrm{~g}, \mathrm{AMF}$ chỉ đạt 120 - 132 bào tử/ $100 \mathrm{~g}$ cơ chất, tương đương với số $\mathrm{AMF}$ ngoài tự nhiên trên cây chủ trường thành. Trong khi đó, nếu nuôi trên ở thể tích lớn hơn thì số lượng bào tử AMF đạt gấp 23 , khi đó bào tử $A$. longula đạt $652 \mathrm{AMF} / 100 \mathrm{~g}$ cơ chất, tiếp đến là $G$. gingatea, số lượng bào tử đạt $548 \mathrm{AMF} / 100 \mathrm{~g}$ cơ chất. Con số này gấp 3-7 lần so với số $\mathrm{AMF}$ phân lập được từ đất trồng ngô trưởng thành ở Hà Nam và Hà Nội. Như vậy việc nhân nuôi $\mathrm{AMF}$ vào cây một cách chủ động đã làm gia tăng số lượng bào tử $\mathrm{AMF}$ đủ để sản xuất làm phân bón sinh học. Tuy nhiên, sử dụng phân bón này có làm tăng năng suất cây trồng hay không thì cần phải có những bước nghiên cứu tiếp theo.

\subsection{Nhân nuôi AMF ngoài đồng ruộng}

Ba loại bào tử $\mathrm{AMF}$ đã lựa chọn ở trên được tiến hành nhân nuôi trong các loại hộp xốp và đưa ra ngoài đồng ruộng, đánh giá khả năng xâm nhiễm của $A M F$ vào rễ cây chủ sau 4 tuần nuôi cấy. Kết quả cho thấy: giá trị IP trong lô thí nghiệm dao động từ 1027 đến 1449, IP trung bình là 1217,8 (Bảng 3.3). Kết quả này tương ứng với một nghiên cứu trước đây của Liu và Luo (1994) [6]. 
Bảng 3.3. Khả năng lây nhiễm và sự phát triển của AMF trên ngô

\begin{tabular}{llllll}
\hline Chế AMF & $\mathrm{N}$ & $\mathrm{K}$ & $\mathrm{W}(\mathrm{g})$ & $\mathrm{S}$ & $\mathrm{IP}$ \\
\hline \multirow{2}{*}{ G.decipien } & 5 & 12 & 16,3 & 168 & 1146 \\
& 6 & 15,5 & 40,3 & 186 & 1449,3 \\
G.gingatea & 6 & 10,5 & 35,5 & 172 & 1027,8 \\
& 5 & 13,5 & 24,3 & 159 & 1259,3 \\
A. longula & 6 & 12,5 & 21,1 & 161 & 1179,8 \\
& 4 & 13,5 & 10,9 & 165 & 1265,3 \\
Glomusmacrocarpum & 5 & 12 & 13,2 & 167 & 1145 \\
Trungbình & 6 & 13 & 35,5 & 211 & 1270,5 \\
ĐC & 5,3 & 12,8 & 24,6 & 173,6 & 1217,8 \\
\hline
\end{tabular}

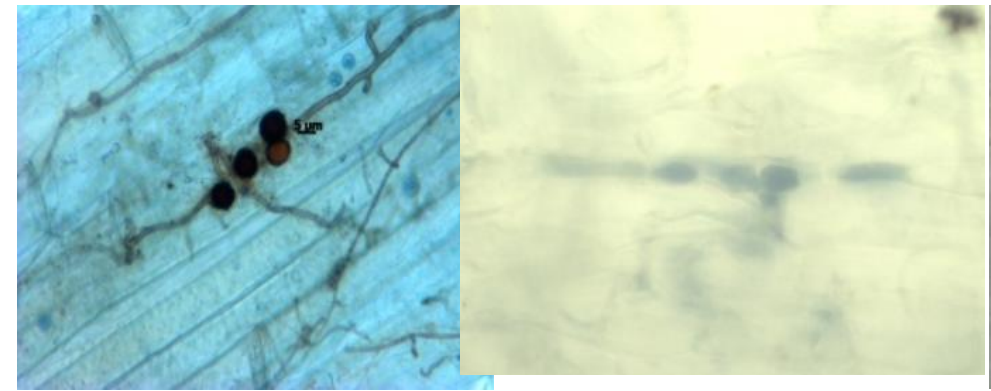

Hình 3.4a. Bào tử và sợi nấm cộng sinh trong rễ ngô.
Hình 3.4b. Sự hình thành bọng AMF trong rễ cây ngô.

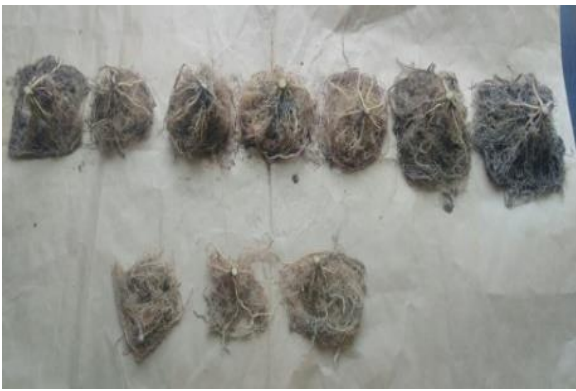

Hình 3.4c. Rễ ngô có bổ sung AMF (trên) và không bổ sung $\mathrm{AMF}$ (dưới).

\section{5. Đánh giá hiệu quả sủ dụng $A M F$ vào sụ phát triển của ngô ngoài đồng ruộng}

Mỗi cây ngô thí nghiệm được bón vào mỗi gốc ngô $100 \mathrm{~g}$ chế phẩm, phần ngô đối chứng không bón chế phẩm AMF. Chăm sóc cây ngô thí nghiệm và ngô đối chứng ở cùng một điều kiện. Quan sát sự sinh trưởng, phát triển của cây ngô, sự hình thành hoa, bắp ngô thấy có sự phát triển vượt trội về chiều cao thân, chiều dài lá, đường kính và chiều dài bắp ngô. Kết quả cho thấy khi có bổ sung AMF khối lượng, chiều cao cây ngô và khối lượng bắp ngô tăng đáng kể so với đối chứng. Trọng lượng khô thân ngô tăng $40 \%$ so với đối chứng, chiều cao thân tăng $58,9 \%$ so với đối chứng, trọng lượng bắp tăng $24,9 \%$ so với đối chứng. Điê̂u này cũng phù hợp với nghiên cứu trước đó của Hajilou và cs (2010) cho rằng khi bổ sung $\mathrm{AMF}$ làm tăng $5 \%$ số lượng hạt bắp [17].

\section{Kết luận}

Trong nghiên cứu này, chúng tôi đã phân lập được 3179 bào tử $\mathrm{AMF}$ từ 15 mẫu đất trồng ngô ở Hà Nội và 15 mẫu đất trồng ngô ở Hà Nam. Chúng thuộc 8 chi và 27 loài, trong đó có 03 chi 12 loài được nghi là mới. Chi Acaulospora, Gigaspora và Glomus là các chi có tần suất xuất hiện cao nhất ở mẫu đất cát ở cả Hà Nội và Hà Nam. Đồng thời chúng tôi cũng đã thành công trong việc nhân nuôi 3 chi này trong phòng thí nghiệm với chỉ tiêu chất lượng $\gg 300 \mathrm{AMF} / 100 \mathrm{~g}$ cơ chất và chế phẩm có khả năng xâm nhiễm vào cây chủ với chỉ số IP > 1000. Khi bổ sung chế phẩm vào cây ngô ngoài đồng ruộng sẽ tăng $40 \%$ trọng lượng, $58,9 \%$ chiều cao thân ngô và $24,9 \%$ trọng lượng bắp. 


\section{Lời cảm ơn}

Nghiên cứu được hỗ trợ kinh phí từ đề tài QG. 16.35 của Đại học Quốc gia Hà Nội.

\section{Tài liệu tham khảo}

[1] Bever JD, Morton JB, Antonovics J, Schultz PA(1996) Host-dependent sporulation and species diversity of Arbuscular Mycorrhiza fungi in a mown grassland, J Ecol 84: 63-71.

[2] Lee J, Lee S \& Young JPW (2008) Improved PCR primers for the detection and identication of Arbuscular Mycorrhizalfungi. FEMS Microbiol Ecol 65:339-349.

[3] Morton JB(1988) Taxonomy of VA mycorrhizal fungi: classification, nomenclature, and identification. Mycotaxon 37: 259-267.

[4] Gerdemann JW and TH Nicolson TH(1963) Spores of mycorrhizal Endogone species extracted from soil by wet-sieving and decanting, Trans. Br. Mycol. Soc. 46: 228-235.

[5] Choi YW, Hyde KD and Ho WH (1999) Single spore isolation of fungi, Fungal Diversity, 3:1- 29.

[6] Liu RJ and Lua XS (1994) "A new method to quantify the inoculum potential of arbuscular mycorrhizal fungi”. New Phytol, 128, 89-92.

[7] Morton JB and Benny GL(1990) Revised classification of Arbuscular Mycorrhizal fungi, a new order Glomales, two new sub-orders Glomineae and Gigasporinae and two new families Acaulosporaceae and Gigasporaceae with an emendation of Glomaceae, Mycotaxon 37: 462- 471.

[8] http://invam.caf.wvu.edu.

[9] Zhao ZW, Wang GH and Yang L(2003) Biodiversity of Arbuscular Mycorrhizal fungi in tropical rain forests of Xishuangbanna, southwest China, Fungal Diversity 13: 225-233.
[10] Brown (2015) Workshop on Biofertilizer. IMBTVNU

[11]Đỗ Thị Xuân (2016) Khảo sát sự xâm nhiễm và sự hiện diện các bào tử nấm rễ nội cộng sinh (AM) trong đất vùng rễ và rễ của cây bắp, mè và ớt được trồng ở Thành phố Cần Thơ. Tạp chí Đại học Cần Tho, 46B: 47-53.

[12]Trần thị Dạ Thảo (2012) Nghiên cứu sự cộng sinh của nấm Mycorrhiza trên cây ngô (Zae Mays L) vùng Đông Nam Bộ. Luận án TS Đại học Nông Lâm TPHCM.

[13] Võ Thị Tú Trinh và Trương Minh (2017) Sự phân bố và xâm nhiễm của nấm rễ nội cộng sinh Arbuscular Mycorrhizae (VAM) trong mẫu rễ và đất trồng bắp tại một số tỉnh đồng bằng sông Cửu Long. Tạp chí Khoa học trường Đại học Cần Thơ. Phần $\mathrm{B}$ : Nông nghiệp, thủy sản và Công nghệ Sinh học, 53:105-111.

[14] Trần Thị Như Hằng, Trần Thị Hồng Hà, Nguyễn Đình Luyện, Posta Katalin, Lê Mai Hương (2012) Phân lập, nhân nuôi lưu giữ và định tên một số nấm rễ nội cộng sinh trên cây lúa và cà chua ở Bắc Việt Nam, Tạp chí Khoa học và Công nghệ 50 (4) 521.

[15] Wang YY, Vestberg M, Walker C, Hurme T, Zhang XP, Lindström K(2008), Diversity and infectivity of Arbuscular Mycorrhizal fungi in agricultural soils of the Sichuan Province of mainland China, Mycorrhiza: 1868.

[16] Guadarrama P and Alvarez-Sanchez FJ(1999)Abundance of Arbuscular Mycorrhizal fungi spores in different environments in a tropical rain forest, Veracruz, Mexico, Mycorrhiza, 258-267.

[17] Hajilou M, Abbasdokht M, Amerian M and Gholami A (2010) Function of biologic fertilizers on growth characteristics, yield and yield components of maize in agriculture ecosystem. The first national congress of sustainability agriculture and healthy crop production, Iran. 


\title{
Isolation of Mycorrhizal Fungi from Maize Cultivation Soil and the Production of Biofertilizer from These Fungi
}

\author{
Le Thi Hoang Yen ${ }^{1}$, Le Hong Anh ${ }^{1}$, Mai Thi Dam Linh ${ }^{2}$, \\ Duong Van Hop ${ }^{1}$ \\ ${ }^{1}$ VNU Institute of Microbiology and Biotechnology, 144 Xuan Thuy, Hanoi, Vietnam \\ ${ }^{2}$ VNU University of Science, 334 Nguyen Trai, Thanh Xuan, Hanoi, Vietnam
}

\begin{abstract}
A total of 3,179 Arbuscular Mycorrhizal Fungus (AMF) spores were isolated from 30 maize cultivation soil samples collected in Hanoi and Ha Nam. The spores were analyzed under a microscope at 200x magnification and grouped into 8 genera with 27 species of AMF according to their morphological characteristics including shape, size, colour and wall structures. Three out of the identified genera with 9 species were regarded as novel taxa and the species of Dentiscutata, Racocetra, Rhizophagus and Septoglomus were, for the first time, reported about in Vietnam. Acaulospora, Gigaspora and Glomus were the dominant genera with the occurence frequency ranging from $13.4 \%$ to $40.2 \%$. A. Longula, G. Decipien, G. Gingatea and Glomusmulticaule were evaluated for their ability to propagate in the maize host. Media containing silica sand, coconut bark and rich soil in different ratios were used for propagating AMF. After 5 weeks' innoculation, Acaulospora showed the best propagation in the medium with silica sand, coconut bark and rich soil mixed in the ratio of 1:1:1, followed by Gingaspora and Glomus. The number of spores propagated from Gingaspora and Acaulospora ranged from 250 to 331 spores/ 100g substrates. The study also shows that AMF could propagate in the host at the IP of 1217.8 and could enhance the innoculated maize's body weight, height and ear by $40.0 \%, 58.9 \%$ and $24.9 \%$, respectively.
\end{abstract}

Keywords: Arbuscular mycorrhizal fungus, diversity, bio-fertilizer, maize root, taxonomy 